\title{
The Diversity Paradox: Immigration and the Colour Line in Twenty-First Century America
}

\author{
by Jennifer Lee and Frank D. Bean \\ New York: Russell Sage Foundation, 2010 \\ ISBN 978-0871540416 \\ Hardcover \$37.50, 240 pp.
}

\author{
Reviewed by Sharon M. Lee \\ Department of Sociology \\ University of Victoria \\ sml@uvic.ca
}

This book by Jennifer Lee and Frank Bean, sociologists at the University of California (Irvine), examines the role of three processes—the "new" (post-1965) immigration, intermarriage trends, and multiracial identity - in increasing racial and ethnic diversity in the U.S. and how these may be contributing to a redrawing of the historical black/white colour line in that country.

The subject of how U.S. racial boundaries may be changing is of great interest to researchers and the general public: the former shown by an extensive research literature, the latter reflected in numerous stories on race and multiraciality in the mass media, including extensive coverage of President Barack Obama's election in 2008 as the first black and multiracial U.S. President. The idea of potentially new colour lines emerging in the U.S., and what this may mean for notions of race, "whiteness," and "blackness," is therefore intriguing for a country where race has been—and, many believe, continues to be—a central organizing principle in daily life.

The book is divided into three parts, with ten chapters. Part I discusses the historical background, theoretical framework, and sociodemographic context for the study. There are four chapters in Part I, including one on racial categories in the U.S. census and the role of the new immigration in altering ethnoracial ${ }^{1}$ diversity in the U.S., particularly in metropolitan areas where immigrants tend to settle. Part II consists of four chapters, which document and describe trends in intermarriage and multiracial identity, and results from interviews with various intermarried and multiracial respondents. Part III contains two chapters: additional analysis in Chapter 9 clarifies the relationships between ethnoracial diversity, intermarriage, multiracial identity, and the diversity paradox of the book's title, and the last chapter is a conclusion that discusses possible future paths for America's colour lines,

1. The authors use the term, "ethnoracial" to refer to the following five categories:

Asians, blacks, Latinos, whites, and others. 
given the evidence. There are also an appendix describing the methodology used, a list of references, and an index.

This volume is a welcome and important addition to the extant literature on ethnoracial diversity in the United States. The authors combine quantitative analysis, based on the 2000 census and 2007 and 2008 American Community Survey data, with qualitative insights from personal interviews with a small sample of intermarried and multiracial respondents in California to support their argument that race in the U.S., historically centered on the black/white divide, is on the cusp of a dramatic redrawing of colour lines. Findings from quantitative analysis contain implications for the role of compositional and structural factors, while qualitative findings point to shifts in attitudes and sociocultural factors.

The quantitative analysis consists of descriptive trends in intermarriage and multiracial reporting, and additional compositional analysis to map the geography of increased ethnoracial diversity brought about by immigration, intermarriage, and multiracial reporting. The quantitative analysis is carefully done and reflects the strong sociological and demographic perspectives brought to the volume by the two primary authors (Lee and Bean) and their co-authors (James Bachmeier and Zoya Gubernskaya in Chapter 4, and Bachmeier in Chapter 9).

The key findings from the quantitative analysis show that the U.S. population is indeed in the midst of dramatic transformations, mainly because of three interrelated processes. First, contemporary immigration has introduced large populations of Latinos or Hispanics and Asians into a population historically made up of a large white majority and small black minority. Latinos, at 15 per cent of the total population, have replaced blacks as the largest minority, and the Asian population has increased from just 1 per cent of the total in 1970 to 5 per cent by 2007 . Second, increased diversity has not dampened the secular trend of increased intermarriage reported by other researchers. This is an interesting finding, given the expectation that increased group size of minority groups would reduce exogamy. Indeed, intermarriage rates by Asians and Latinos (the two largest immigrantbased populations) continue to exceed those of blacks, although intermarriage rates have increased for all groups.

Finally, the trend of increased reporting of multiracial identity appears to have continued since the landmark decision to allow the reporting of more than one race in the 2000 census, despite an apparent decline if one were to simply compare the 2.4 per cent who reported more than one race in the 2000 census and the 2.2 per cent in the 2008 American Community Survey. The authors suggest that the apparent decline was mostly due to respondents' confusion over the "other" race category that was offered as an option, and increased immigration. Other reasons not discussed by the authors are that American Community Survey data are not directly comparable with decennial census data, and the well-known instability of racial and ethnic origin responses because of period, context, instrument, and other factors.

The qualitative data derived from interviews with 36 intermarried couples and 46 multiracial respondents residing in California provided additional insights into how racial boundaries may be changing. The main qualitative findings reveal stark differences separating couples with one black partner from other intermarried couples, and between black multiracials (that is, a multiracial person who re- 
ported black and another background) and Asian and Latino multiracials (that is, a multiracial person who reported either Asian or Latino and another background). Intermarried blacks indicated greater opposition and difficulties from their nonblack partners' families and, for some, from their own families, while intermarried Asians and Latinos generally reported that their race or background was not an issue for their own or their partners' families. For intermarried Asians and Latinos, marriage with whites was perceived as part of "becoming American."

A similar pattern emerged from interviews with multiracial respondents. Black/white multiracials reported that they usually identified as black or perhaps multiracial, but seldom as white, whereas Asian/white and Latino/white multiracials expressed greater flexibility in their choice of racial identity. For these multiracials, racial identity appeared to be more situational and symbolic than ascribed.

The "diversity paradox" of the book's title refers to what the authors termed "black exceptionalism." Blacks intermarry at a lower rate than Asians and Latinos, intermarried blacks are more likely to experience negative responses to their exogamy, and multiracial blacks are more constrained in their choice of racial identity. To further clarify the relationship between increased diversity, intermarriage, and multiracial identity, the authors conducted additional quantitative analysis with data from the 1990 and 2000 censuses and 2007 and 2008 American Community Surveys, using census metropolitan areas as the unit of analysis. Findings from path analysis confirmed that increased ethnoracial diversity contributes to loosening of group boundaries for blacks, Asians, and Latinos, but a pattern of black exceptionalism persists: increased size of the black population is related to lower multiracial reporting, a finding that the authors attribute to a greater perceived threat from an increased black population and, therefore, a hardening of racial boundaries between blacks and others.

In the concluding chapter, the authors discuss the broader and long-term implications of the findings for the colour line in 21st-century America. Will the concept and group boundary of "white" expand to incorporate Asians and Latinos, but with blacks remaining on the other side of an enduring white/black divide? Or will Asians and Latinos remain neither white nor black, but in fact more like white - an option that again leaves blacks on the other side? The authors believe that the evidence detailed in this volume suggests that a black/non-black colour line is re-emerging in the U.S., with profound implications for the status and experience of all ethnoracial groups, but particularly for blacks who remain marginalized on one side-hence, the sub-heading for the chapter: plus ça change, plus c'est la même chose.

This is an impressive book and warrants reading by all who are interested in contemporary racial and ethnic demography in the U.S. Findings from the extensive empirical analyses are thoughtfully discussed and theoretically informed. However, no work is perfect. One minor complaint is the repetition of material (in some cases, the same sentences and phrases) in different parts of the book. A tighter editing would have avoided this. A more important issue is the authors' overly strong conclusions about their findings.

Specifically, while multiracial Asians and Latinos appear to have greater flexibility in choice of ethnoracial identity, this population remains a small minority of the Asian and Latino populations (around 12-14 per cent of Asians and per- 
haps 18 per cent of Latinos report more than one race). To conclude from the quantitative findings, and additional qualitative findings, based on interviewing 16 Asian/white and 8 Latino/white multiracials in California that Asians and Latinos may be "next in line to become white" seems a bit of a stretch. What about the ethnoracial identity and experience of the over 80 per cent of monoracial Asians and Latinos? It is doubtful that in their daily experiences, monoracial Asians and Latinos are perceived and treated as more like whites than as ethnoracial minorities in a U.S. society with its obvious ethnoracial hierarchy. Studies of several more generations of exogamous and multiracial Asians and Latinos are needed before one can conclude that a new colour line, be it an expanded white boundary that includes multiracial Asians and Latinos (leading to a different white/black divide), or a black/non-black line, has emerged. It therefore remains to be seen if and what new colour lines are emerging in 21st-century America. 